\title{
Resonant modes of the motion of a cylindrical reservoir on a movable pendulum suspension with a free-surface liquid
}

\author{
Limarchenko O., Nefedov A. \\ Taras Shevchenko Kyiv National University, \\ 64/13 Volodymyrska Str., Kyiv, 01033, Ukraine
}

(Received 28 September 2018)

\begin{abstract}
The article deals with an investigation of the system of "reservoir - liquid with a free surface", when the reservoir is fixed on pendulum suspension, which suspension point performs a given motion. The system behavior is studied for the below-resonant, nearresonant and above-resonant modes. The description of the system behavior is done based on a nonlinear model of motion, which takes into account the combined character of motion of the system components. The numerical modeling shows that general regularities of the system behavior coincide qualitatively with known experiments.
\end{abstract}

Keywords: liquid oscillations, reservoir on pendulum suspension, near-resonant modes of motion, amplitude modulation.

2000 MSC: 76B07, 76B99

UDC: 532.595

DOI: $10.23939 / \mathrm{mmc} 2018.02 .178$

\section{Introduction}

Modern studies in the field of dynamics of structures with liquid show that combined modes of system motion result in a considerable change of dynamical properties of structures with liquid. This manifests itself both at the linear level (change of frequencies) and in the new tendencies of the system behavior in resonant modes. Considering a combined character of motion leads to the considerable increase of frequencies of motion of a free surface of a liquid relative to antisymmetric normal modes, at the same time frequencies of the rest of normal modes do not change. This results in changing of the order of distribution of frequencies of normal modes, when the frequency of the first antisymmetric normal mode becomes not the lowest one and, therefore, the manifestation of its resonant is not so clear.

In the case of a movable pendulum suspension of the cylindrical reservoir with liquid, the lowest frequency of combined system motion is closer to the pendulum suspension frequency. Therefore, we study the system behavior for the given motion of the suspension point according to the harmonic law in a vicinity of this frequency.

\section{Mathematical model}

The mathematical model of the system is selected based on a nonlinear dynamical model of combined motion of the reservoir with liquid. The reservoir can perform translational and rotational motion. A liquid is supposed to be ideal, homogeneous, incompressible, and its motion is supposed to be potential. The reservoir is modeled as an absolute rigid body with a cylindrical cavity. The general form of the dynamical model aimed at the study of transient processes was developed in [1]. The specific peculiarity of the model in our problem is considering of a translational motion as given and the presence of a movable pendulum suspension. In this case, we consider as combined both the angular motion of the reservoir and a liquid sloshing. The general form of equations in parameters of angular motion $\alpha_{i}$ of the reservoir and the amplitude parameters of excitation of normal modes of oscillations of a free 
surface of the liquid $a_{i}$ is the following

$$
\begin{gathered}
\sum_{i} \ddot{a}_{i}\left(\delta_{i r}+\sum_{j} a_{j} A_{r i j}^{3}+\sum_{j, k} a_{j} a_{k} A_{r i j k}^{4}\right)+\frac{1}{2 \alpha_{r}^{v}} \sum_{s=1}^{3} \ddot{\alpha}_{s}\left[\sum_{p=1}^{3} \frac{\partial \omega_{p}}{\partial \dot{\alpha}_{s}}\left(E_{p r}^{1 *}+\sum_{i} a_{i} E_{p r i}^{2 *}+\sum_{i, j} a_{i} a_{j} E_{p r i j}^{3 *}\right)\right] \\
=-k_{r} \dot{a}_{r}-\frac{1}{\alpha_{r}^{v}} \ddot{\boldsymbol{\varepsilon}} \cdot\left(\boldsymbol{B}_{r}^{1}+\sum_{i} a_{i} \boldsymbol{B}_{r i}^{2}+\sum_{i, j} a_{i} a_{j} \boldsymbol{B}_{r i j}^{3}+\sum_{i, j, k} a_{i} a_{j} a_{k} \boldsymbol{B}_{r i j k}^{4}\right) \\
+\sum_{i, j} \dot{a}_{i} \dot{a}_{j} C_{i j r}^{3}+\sum_{i, j, k} \dot{a}_{i} \dot{a}_{j} a_{k} C_{i j k r}^{4}+\frac{1}{2 \alpha_{r}^{v}} \sum_{p, s=1}^{3} \omega_{p} \omega_{s}\left(E_{p s r}^{2}+2 \sum_{i} a_{i} E_{p s i r}^{3}\right) \\
+\frac{1}{2 \alpha_{r}^{v}} \sum_{p=1}^{3} \omega_{p}\left[\sum_{i} \dot{a}_{i}\left(E_{p i r}^{2 *}-E_{p r i}^{2 *}\right)+2 \sum_{i, j} \dot{a}_{i} a_{j}\left(E_{p i j r}^{3 *}-E_{p r i j}^{3 *}\right)\right] \\
+\frac{1}{2 \alpha_{r}^{v}} \sum_{p=1}^{3} \omega_{p}^{(k)}\left(E_{p r}^{1 *}+\sum_{i} a_{i} E_{p r i}^{2 *}\right)+\dot{\varepsilon} \cdot\left(\sum_{i} \dot{a}_{i} \boldsymbol{D}_{i r}^{2}+\sum_{i, j} \dot{a}_{i} a_{j} \boldsymbol{D}_{i j r}^{3}+\sum_{i, j, k} \dot{a}_{i} a_{j} a_{k} \boldsymbol{D}_{i j k r}^{4}\right) \\
+\frac{1}{2 \alpha_{r}^{v}} \dot{\varepsilon} \sum_{p=1}^{3} \omega_{p}\left(\boldsymbol{F}_{p r}^{2}+2 \sum_{i} a_{i} \boldsymbol{F}_{p i r}^{3}+3 \sum_{i, j} a_{i} a_{j} \boldsymbol{F}_{p i j r}^{4}\right)
\end{gathered}
$$

$-\frac{\alpha_{r}^{c}}{\alpha_{r}^{v}} g\left(\sin \alpha_{1} \sin \alpha_{3}-\cos \alpha_{1} \sin \alpha_{2} \cos \alpha_{3}\right)-\frac{\alpha_{r}^{s}}{\alpha_{r}^{v}} g\left(\sin \alpha_{1} \cos \alpha_{3}+\cos \alpha_{1} \sin \alpha_{2} \sin \alpha_{3}\right)-\frac{N_{r}}{\alpha_{r}^{v}} g \cos \alpha_{1} \cos \alpha_{2}$

$$
-\frac{\sigma}{\rho \alpha_{r}^{v}}\left[\lambda \cos \theta_{1}+\varkappa_{r}^{2} N_{r} a_{r}-\frac{1}{4} \sum_{i, j, k}\left(\delta_{i j k r}^{4}+\delta_{r i j k}^{4}\right) a_{i} a_{j} a_{k}\right]
$$

$$
\begin{gathered}
\sum_{i} \ddot{a}_{i}\left[\sum_{p=1}^{3} \frac{\partial \omega_{p}}{\partial \dot{\alpha}_{r}}\left(\boldsymbol{E}_{p i}^{1 *}+\sum_{j} a_{j} \boldsymbol{E}_{p i j}^{2 *}+\sum_{i, k} a_{j} a_{k} \boldsymbol{E}_{p i j k}^{3 *}\right)\right] \\
+\sum_{n=1}^{3} \ddot{\alpha}_{n}\left[2 \sum_{p, s=1}^{3} \frac{\partial \omega_{p}}{\partial \dot{\alpha}_{r}} \frac{\partial \omega_{s}}{\partial \dot{\alpha}_{n}}\left(\frac{1}{\rho} I_{\mathrm{res}}^{p s}+E_{p s}^{2}+\sum_{i} a_{i} E_{p s i}^{2}+\sum_{i, j} a_{i} a_{j} E_{p s i j}^{3}\right)\right] \\
=-2 \ddot{\varepsilon} \sum_{p=1}^{3} \frac{\partial \omega_{p}}{\partial \dot{\alpha}_{r}}\left(\boldsymbol{F}_{p}^{1}+\sum_{i} a_{i} \boldsymbol{F}_{p i}^{2}+\sum_{i, j} a_{i} a_{j} \boldsymbol{F}_{p i j}^{3}+\sum_{i, j, k} a_{i} a_{j} a_{k} \boldsymbol{F}_{p i j k}^{4}\right) \\
+2 \sum_{p, s=1}^{3}\left(\omega_{p, r}^{*} \omega_{s}+\omega_{p}^{(k)} \frac{\partial \omega_{s}}{\partial \dot{\alpha}_{r}}\right)\left(\frac{1}{\rho} I_{\mathrm{res}}^{p s}+E_{p s}^{2}+\sum_{i} a_{i} E_{p s i}^{2}+\sum_{i, j} a_{i} a_{j} E_{p s i j}^{3}\right) \\
+\sum_{p=1}^{3} \omega_{p, r}^{*}\left(\sum_{i} \dot{a}_{i} E_{p i}^{1 *}+\sum_{i j} \dot{a}_{i} a_{j} E_{p i j}^{2 *}+\sum_{i, j, k} \dot{a}_{i} a_{j} a_{k} E_{p i j k}^{3 *}\right)+2 \dot{\varepsilon} \cdot \sum_{p=1}^{3} \omega_{p, r}^{*}\left(\boldsymbol{F}_{p}^{1}+\sum_{i} a_{i} \boldsymbol{F}_{p i}^{2}+\sum_{i, j} a_{i} a_{j} \boldsymbol{F}_{p i j}^{3}\right) \\
-2 \sum_{p, s=1}^{3} \frac{\partial \omega_{p}}{\partial \alpha_{r}}\left(\sum_{i} \dot{a}_{i} E_{p s i}^{2}+2 \sum_{i, j} \dot{a}_{i} a_{j} E_{p s i j}^{3}\right)-\sum_{p=1}^{3} \frac{\partial \omega_{p}}{\partial \dot{\alpha}_{r}}\left(\sum_{i, j} \dot{a}_{i} \dot{a}_{j} E_{p i j}^{2 *}+2 \sum_{i, j, k} \dot{a}_{i} \dot{a}_{j} a_{k} E_{p i j k}^{3 *}\right) \\
-2 \dot{\varepsilon}_{p=1}^{3} \frac{\partial \omega_{p}}{\partial \dot{\alpha}_{r}}\left(\sum_{i} \dot{a}_{i} \boldsymbol{F}_{p i}^{2}+2 \sum_{i, j} \dot{a}_{i} a_{j} \boldsymbol{F}_{p i j}^{3}\right)+2 g \frac{\partial}{\partial \alpha_{r}}\left[\left(\cos \alpha_{1} \sin \alpha_{2} \cos \alpha_{3}-\sin \alpha_{1} \sin \alpha_{3}\right)\left(\sum_{i} a_{i} \alpha_{i}^{c}+H l^{c}\right)\right. \\
\left.-\left(\cos \alpha_{1} \sin \alpha_{2} \sin \alpha_{3}+\sin \alpha_{1} \cos \alpha_{3}\right)\left(\sum_{i} a_{i} \alpha_{i}^{s}+H l^{s}\right)\right] \\
+\frac{2 g}{\rho}\left(M_{r} h_{r}+M_{1} h_{1}\right) \frac{\partial}{\partial \alpha_{r}}\left(\cos \alpha_{1} \cos \alpha_{2}\right)+\frac{2 M_{r}}{\rho} . \quad(2)
\end{gathered}
$$


The denotations in the systems (1), (2) are selected according to [1]. Here all denotations with indexes are computed as integrals over undisturbed free surface of liquid from normal modes of liquid oscillations and the Stokes-Zhukovsky potential. In the mathematical sense, this system represents a nonlinear system of ordinary differential equations, which are linear according to the second derivatives of unknowns. This property makes it possible to reduce the system to the Cauchy form and solve it numerically by the Runge-Kutta procedure.

\section{Numerical results}

For numerical examples, we choose the following parameters of the system. The modeling was done based on a mathematical model with 12 normal modes of oscillations of a free surface of liquid. The radius of a free surface $R=1 \mathrm{~m}$, the liquid depth is $H=R$, the ratio of masses of the reservoir and liquid is $M_{r}=0.1 M_{l}$, the parameters of the inertial tensor are chosen following [1] (thickness of the tank walls is $1.5 \mathrm{~cm}$, thickness of the tank bottom and cover is $1.2 \mathrm{~cm}$, the height of the reservoir is $1.5 R$ ), the suspension length of the pendulum is $l=R, l=2 R, l=8 R$ (for comparison). The angular oscillations of the system are considered to be plane and they are characterized only by a single angle $\alpha_{1}=\phi$. We do not use the dimensionless time since the system frequency for different examples varies, therefore, for comparison of different examples we use the real time. Further the dimension of frequencies is given in $1 / \mathrm{sec}$, the liquid elevation is normalized relative to the reservoir radius $R$.

To study the resonant properties of the system of reservoir - liquid on a pendulum suspension, it is necessary initially to study the frequencies of oscillations of the system in the case of combined motion of its components. The results of these calculations are shown in Table. For three suspension lengths $(1,2,8)$, we compute frequencies of oscillations (three variants). The second and third columns show normal frequencies of oscillations of the system in the case of not combined motion, so, these are the partial frequencies. The fourth column shows the frequencies of combined motion of the system in the case when the translational motion of the system is given, but the sloshing and the angular motion of the system are coupled. The fifth column shows the frequencies of combined motion of the system when the translational and rotational motions and the sloshing are coupled. In the fourth and fifth columns, we show two frequencies corresponding to the combined motion, here the upper value of frequency is closer to the partial frequency of pendulum oscillations, and the lower ones correspond to the sloshing (the first normal mode of oscillations with respect to the antisymmetric mode). As it is seen from Table, the normal frequency of angular oscillations changes slightly (about 10\%), however, the frequency of sloshing can change by 1.5 (column 4) and 3 (column 5) times. In this case, the frequency of the first antisymmetric normal mode becomes even greater than the frequencies of sloshing, corresponding to the circular numbers $m=2$ and $m=0$. Therefore, the sharpness of manifestation of the resonance with respect to the first antisymmetric normal mode is weaker than the resonance with respect to pendulum frequency.

\begin{tabular}{ccccc}
\hline Variant & $\begin{array}{c}\text { Partial frequency } \\
\text { of liquid }\end{array}$ & $\begin{array}{c}\text { Partial frequency of } \\
\text { the pendulum }\end{array}$ & $\begin{array}{c}\text { Frequency of combined } \\
\text { oscillations without } \\
\text { translational motion }\end{array}$ & $\begin{array}{c}\text { Frequency of } \\
\text { completely combined } \\
\text { oscillations }\end{array}$ \\
\hline$l=1$ & 4.14431 & 2.47842 & 2.24312 & 2.26729 \\
\hline$l=2$ & 4.14431 & 1.96189 & 6.69986 & 16.63085 \\
\hline$l=8$ & 4.14431 & 1.07442 & 1.85304 & 1.86112 \\
& & & 6.10821 & 12.45135 \\
\hline
\end{tabular}

Further we analyze the system input into the resonance in the case of the pendulum suspension length $l=2 R$ for the below-resonance mode (excitation with frequency $75 \%$ of the frequency of normal 
oscillations relative to the angular mode of motion, Figs. 1,2), for the near resonance mode (excitation with frequency $102 \%$ of the frequency of normal oscillations relative to the angular mode of motion, Figs. 3,4) and for the above-resonance mode (excitation with frequency $125 \%$ of the frequency of normal oscillations relative to the angular mode of motion, Figs. 5,6). Here figures with odd numbers correspond to variation of the angular coordinate in time, figures with even numbers correspond to variation of elevation of liquid near tank wall in time.

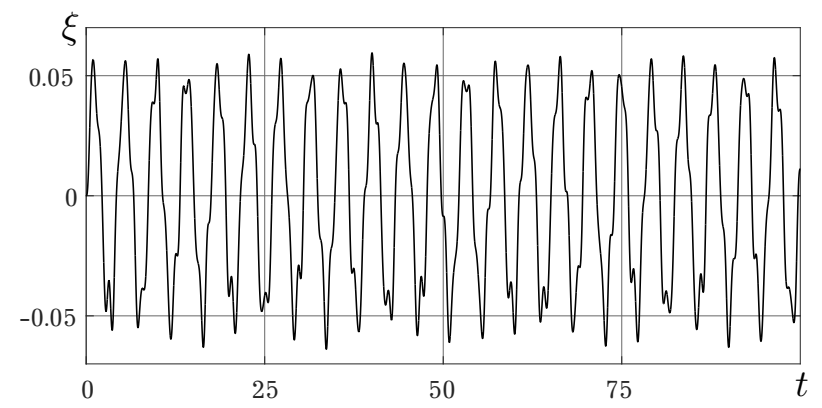

Fig. 1. Elevation of a free surface for the belowresonance mode

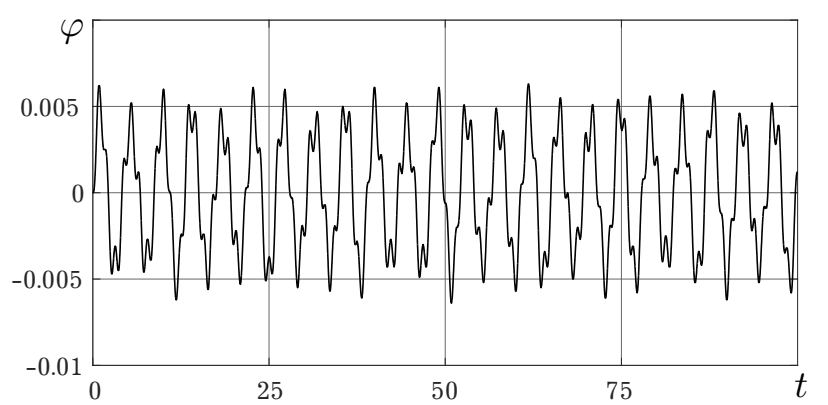

Fig. 2. Angular oscillations for the below-resonance mode

First of all, it is necessary to note that in spite of conclusions of numerous articles [2-4] for all modes of motion the input to the steady mode form of motion does not take place. This property is confirmed by the experimental results [5-8] and was predicted by theoretical results of articles $[9,10]$ for translational and angular modes of motion of the reservoir.

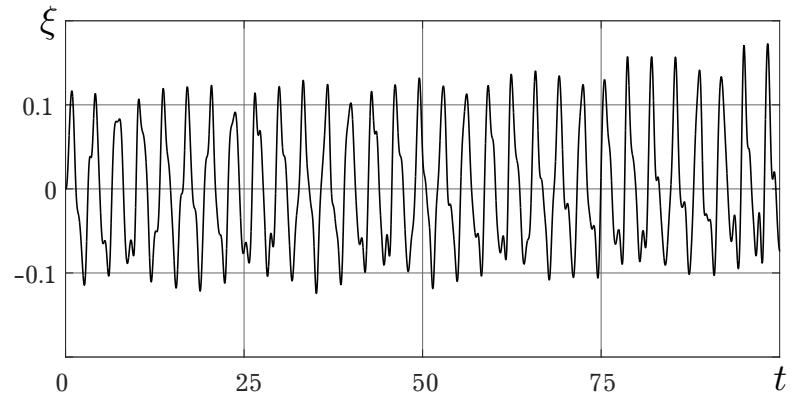

Fig. 3. Elevation of a free surface for the nearresonance mode

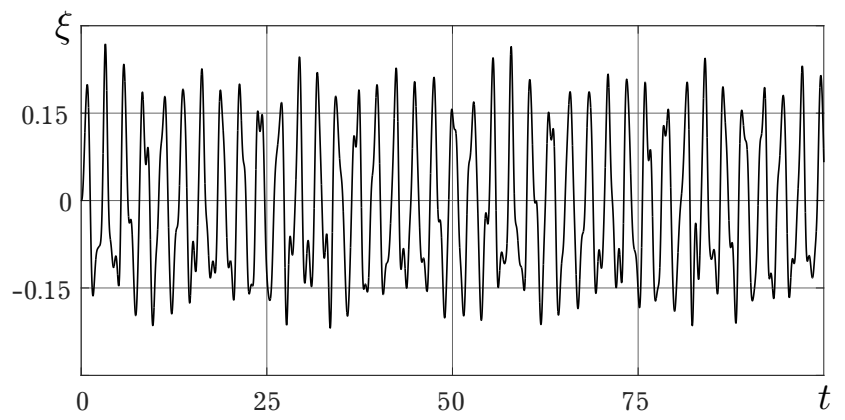

Fig. 5. Elevation of a free surface for the aboveresonance mode

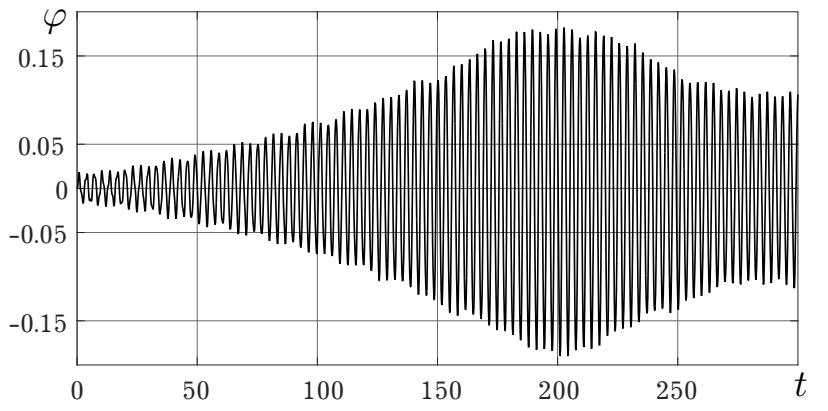

Fig. 4. Angular oscillations for the near-resonance mode

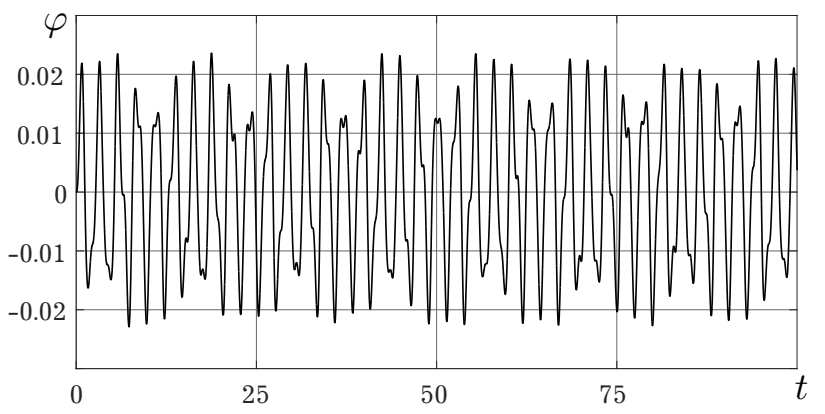

Fig. 6. Angular oscillations for the above-resonance mode

The numerical results show that for the below-resonance mode of motion, the drift of the mean values of variation of both the inclination angle and the elevation of liquid occurs, the presence of 
high-frequency normal modes of motion is evident. The effect of modulation is comparatively weak. In the near-resonance mode, the period of modulation is very great, but the effect of the mean value drift and the presence of high-frequency modes of oscillations is weakly observed. For the above-resonance mode of motion, the effect of modulation of oscillations is considerable. At the same time, the presence of high-frequency modes of oscillations is also evident.

\section{Conclusions}

For the problem of a complex motion of the system of "reservoir - liquid with a free surface" on a pendulum suspension, we consider the case when for a part of the system motion parameters (for parameters of translational motion of the point of suspension) the law of motion is given in advance, and the liquid oscillations together with a rotational motion of the reservoir are considered within the framework of the combined mode of the motion. In this case, the frequencies of normal oscillations considerably differ from partial frequencies of motion of the system components. The obtained results of the system behavior in the below-, near- and above-resonance modes of motion are in good qualitative correlation with known theoretical and experimental results.

[1] Limarchenko O. S., Yasinskiy V. V. Nonlinear dynamics of structures with liquid. National Technical University of Ukraine "KPI" (1997), (in Russian).

[2] Faltinsen O. M., Rognebakke O.M., Timokha A. N. Resonant three-dimensional nonlinear sloshing in a square-base basin. J. Fluid Mech. 487, 1-42 (2003).

[3] Ibrahim R. A. Liquid sloshing dynamics: theory and applications. Cambridge University Press (2005).

[4] Lukovskiy I. A. Introduction to nonlinear dynamics of a rigid body with cavities containing liquid. Naukova dumka, Kiev (1990), (in Russian).

[5] Faltinsen O. M., Rognebakke O. M., Timokha A. N. Transient and steady-state amplitudes of resonant threedimensional sloshing in a square base tank with a finite fluid depth. Physics of fluids. 18 (1), 012103 (2006).

[6] Mikishev G. N., Rabinovich B. I. Dynamics of rigid bodies with cavities partially filled by liquid. Mashinostroenie, Moscow (1968), (in Russian).

[7] Pal P. Sloshing of liquid in partially filled container - an experimental study. International Journal of Recent Trends in Engineering. 1 (6), 1-5 (2009).

[8] Zhang Ch., Li Y., Meng Q. Fully nonlinear analysis of second order sloshing resonance in a three-dimensional tank. Computers \& Fluids. 116, 88-104 (2015).

[9] Limarchenko O.S., Gubskaya V.V. Problem of forced nonlinear oscillations of the reservoir of truncated conic shape, partially filled with liquid. Bulletin of Kiev National University. 1 (4), 73-76 (2012).

[10] Lymarchenko O.S., Semenovych K. O. Energy redistribution between the reservoir and liquid with free surface for angular motions of the system. Journal of Mathematical Sciences. 222 (3), 296-303 (2017). 


\title{
Резонансні режими руху циліндричного резервуару на рухомому маятниковому підвісі з рідиною з вільною поверхнею
}

\author{
Лимарченко О., Нефьодов О. \\ Київсъкий начіональний університет імені Тараса Шевченка, \\ вул. Володимирсъка, 64/13, Київ, 01033, Украӥна
}

Досліджено систему "резервуар - рідина з вільною поверхнею”, коли резервуар знаходиться на маятниковому підвісі з точкою підвісу, що виконує заданий рух. Вивчено поведінку системи для дорезонансного, білярезонансного і зарезонансного режимів. Описано поведінку системи на основі нелінійної моделі руху, згідно з якою приймається до уваги сумісний характер руху компонент системи. Чисельне моделювання показало, що загальні закономірності поведінки системи якісно узгоджуються 3 відомими експериментами.

Ключові слова: коливання рідини, резервуар на маятниковому підвісі, білярезонансні режими руху, амплітудна модуляиія.

2000 MSC: 76B07, 76B99

УдК: 532.595 